\title{
KEEFEKTIFAN E-LEARNING SEBAGAI MEDIA PEMBELAJARAN (STUDI EVALUASI MODEL PEMBELAJARAN E-LEARNING SMK TELKOM SANDHY PUTRA PURWOKERTO)
}

\author{
Numiek Sulistyo Hanum \\ Program Studi Pendidikan Teknologi dan Kejuruan PPs UNY \\ numiekhanum@gmail.com
}

\begin{abstract}
Abstrak
Penelitian ini bertujuan untuk (1) mendeskripsikan standar mutu pelaksanaan e-learning sebagai media pembelajaran yang efektif; (2) mengidentifikasi keefektifan perencanaan pembelajaran elearning; (3) mengidentifikasi keefektifan perancangan dan pembuatan materi pembelajaran elearning; (4) mengidentifikasi keefektifan metode penyampaian pembelajaran e-learning; (5) mengidentifikasi keefektifan pelaksanaan dan interaktivitas pembelajaran e-learning; (6) mengidentifikasi keefektifan evaluasi pelaksanaan e-learning; (7) mengetahui faktor penghambat dan pendukung pelaksanaan e-learning sebagai media pembelajaran.

Penelitian ini merupakan penelitian evaluasi dengan model evaluasi discrepancy. Data dikumpulkan melalui angket dan observasi, kemudian data dianalisis secara deskriptif. Keberhasilan program diukur dengan kriteria absolute, yakni standar pelaksanaan pembelajaran e-learning yang telah ditetapkan sebelumnya dari standar mutu penyelenggaraan e-learning yang ideal. Analisis deskripsi data mendiskripsikan dan memaknai keefektifan e-learning sebagai media pembelajaran di SMK Telkom Sandhy Putra Purwokerto dari tiap-tiap data ubahan dan sub ubahan, yaitu nilai rerata pada standar variabel penelitian. Masing-masing ubahan dibandingkan dengan acuan kriteria yang telah ditentukan berdasarkan rata-rata ideal dan simpangan baku ideal yang dapat dicapai oleh instrumen. Responden dari penelitian ini adalah guru dan siswa SMK Telkom Sandhy Putra Purwokerto yang terlibat langsung dengan pembelajaran e-learning. Hasil penelitian menunjukkan bahwa pelaksanaan pembelajaran e-learning di SMK Telkom Sandhy Putra Purwokerto sesuai dengan standar mutu pelaksanaan e-learning pada komponen perencanaan pembelajaran cukup efektif dengan kecenderungan 77,57\%; komponen perancangan dan pembuatan materi cukup efektif dengan kecenderungan 75,14\%; komponen penyampaian pembelajaran e-learning cukup efektif dengan kecenderungan 75\%; komponen interaksi pembelajaran cukup efektif dengan kecenderungan 66,10\%; dan komponen evaluasi pelaksanaan pembelajaran e-learning cukup efektif dengan kecenderungan 69,01\%. Secara keseluruhan dapat disimpulkan bahwa pelaksanaan pembelajaran e-learning sebagai media pembelajaran di SMK Telkom Sandhy Putra Purwokerto cukup efektif dengan tingkat kecenderungan 77,27\%. Hal ini menunjukkan bahwa pelaksanaan pembelajaran e-learning di SMK Telkom Sandhy Putra Purwokerto tidak sepenuhnya efektif bagi semua guru di SMK Telkom Sandhy Putra Purwokerto, dikarenakan beberapa faktor dari pelaksanaannya yang belum optimal.
\end{abstract}

Kata kunci : keefektifan, e-learning, media pembelajaran, discrepancy 


\title{
THE EFFECTIVENESS OF E-LEARNING AS INSTRUCTIONAL MEDIA (EVALUATION STUDY OF E-LEARNING INSTRUCTIONAL MODEL INSMK TELKOM SANDHY PUTRA PURWOKERTO)
}

\author{
Numiek Sulistyo Hanum \\ Graduate School, Yogyakarta State University \\ numiekhanum@gmail.com
}

\begin{abstract}
This study aims to: (1) describe the quality standard of e-learning as effective instructional media, (2) identify the effectiveness of e-learning instructional plan, (3) identify the effectiveness of designing and developing the e-learning materials, (4) identify the effectiveness of delivery method of the e-learning instructional strategy, (5) identify the effectiveness of implementation and interactivities of e-learning instructional, (6) identify the effectiveness of evaluation of the elearning process, and (7) identify the inhibiting and supporting factors in the implementation of elearning as instructional media.
\end{abstract}

This study is an evaluation research using the discrepancy evaluation model. The data were collected through questionnaire and observation, and analyzed descriptively. The success of the program was measured using absolute criteria, i.e. the standard process of e-learning instruction determined by the ideal standard of the quality of e-learning process. The descriptive data analysis described and interpreted the effectiveness of e-learning as instructional media in SMK Telkom Sandhy Putra Purwokerto by each alteration and subalteration data, i.e the average value in the standard of the research variable. Each alteration was compared with criterion standards determined based on the ideal mean and standard deviation obtained by the instrument. The respondents were teachers and students of SMK Telkom Sandhy Putra Purwokerto directly involved in the e-learning instruction.

The results show that the implementation of e-learning in SMK Telkom Sandhy Putra Purwokerto based on the quality standard of e-learning implementation on the component of instructional plan is quite effective with the tendency of 77.57\%; the component of designing and developing the material is quite effective with the tendency of $75.14 \%$; the component of delivery method of instructional strategy is quite effective with the tendency of $75 \%$; the component of interactivities is quite effective with the tendency of 66.10\%; and the component of evaluation of e-learning process is quite effective with the tendency of $69.01 \%$. Overall it can be concluded that the implementation of e-learning as instructional media in SMK Telkom Sandhy Putra Purwokerto is quite effective with the tendency of $77.27 \%$. This study indicates that the implementation of elearning instruction at SMK Telkom Sandhy Putra Purwokerto is not completely effective, because several factors of implementation are not optimal

Keywords: effectiveness, e-learning, instructional media, discrepancy 


\section{PENDAHULUAN}

Penerapan suatu model pembelajaran memiliki satu komponen yang perlu diperhatikan agar suatu model pembelajaran dapat berkesinambungan dan memberikan pengaruh dalam pelaksanaannya. Komponen tersebut yaitu desain, aplikasi/implementasi, dan manajemen atau maintenance. Berkaitan dengan pembelajaran, pemanfaatan teknologi informasi dalam hal ini e-learning diperlukan tidak hanya pendidik yang terampil memanfaatkan teknologi serta teknologi untuk pembuatan bahan ajar, akan tetapi diperlukan suatu rancangan agar dapat melaksanakan pembelajaran dengan efektif. Dalam sebuah rancangan pembelajaran (desain instruksional) terdapat suatu proses untuk memandu pelaku (aktor) untuk mendesain, mengembangkan, menerapkan konten e-learning dengan memanfaatkan infrastruktur dan aplikasi $e$ learning yang tersedia. Pada tahap selanjutnya dalam implementasi e-learning terdapat tahap evaluasi yang dimanfaatkan untuk merevisi atau penyesuaian terhadap tahap-tahap sebelumnya. Desain instruksional merupakan proses dinamis yang dapat berubah-ubah sesuai dengan informasi dan evaluasi yang diterima bertujuan untuk meningkatkan hasil pembelajaran peserta didik sehingga tujuan pembelajaran dapat tercapai.

Salah satu sekolah kejuruan yang secara konsisten ingin meningkatkan mutu dan kualitas pendidikan dengan memanfaatkan teknologi informasi dan komunikasi adalah SMK Telkom Sandhy Putra Purwokerto. SMK Telkom Sandhy Putra Purwokerto merupakan sekolah kejuruan di bidang telekomunikasi yang telah mengembangkan model pembelajaran e-learning. Pemanfaatan e-learning pada sebuah pendidikan kejuruan seperti Sekolah Menengah Kejuruan sangat dibutuhkan untuk membantu guru dalam meningkatkan proses pembelajaran. Seperti telah diketahui, pembelajaran di sekolah kejuruan mempunyai waktu pembelajaran praktik yang lebih banyak dibandingkan dengan pembelajaran teori atau pembelajaran di dalam kelas. Dengan memanfaatkan $e$ learning sebagai media pembelajaran, dapat difungsikan sebagai pelengkap (komplemen) maupun suplemen untuk meningkatkan pembelajaran di dalam kelas sehingga dapat membantu meningkatkan pemahaman siswa terhadap materi dan meningkatkan kegiatan pembelajaran di sekolah kejuruan.

Penelitian ini bertujuan mendeskripsikan standar mutu pelaksanaan e-learning sebagai media pembelajaran yang efektif, mengidentifikasi keefektifan perencanaan pembelajaran e-learning, mengidentifikasi keefektifan perancangan dan pembuatan materi pembelajaran $e$-learning, mengidentifikasi keefektifan penyampaian pembelajaran $e$ learning, mengidentifikasi keefektifan pelaksanaan dan interaktivitas pembelajaran $e$ learning, mengidentifikasi keefektifan evaluasi pelaksanaan e-learning, serta mengetahui faktor penghambat dan pendukung pelaksanaan pembelajaran e-learning

\section{E-learning (Pengertian, Konsep, dan Model)}

E-learning merupakan salah satu bentuk model pembelajaran yang difasilitasi dan didukung pemanfaatan teknologi informasi dan komunikasi. E-learning mempunyai ciri-ciri, antara lain (Clark \& Mayer 2008: 10): 1) memiliki konten yang relevan dengan tujuan pembelajaran; 2) menggunakan metode instruksional, misalnya penyajian contoh dan latihan untuk meningkatkan pembelajaran; 3) menggunakan elemen-elemen media seperti kata-kata dan gambar-gambar untuk menyampaikan materi pembelajaran; 4) memungkinkan pembelajaran langsung berpusat pada pengajar (synchronous e-learning) atau di desain untuk pembelajaran mandiri (asynchronous e-learning); 5) membangun pemahaman dan keterampilan yang terkait dengan tujuan pembelajaran baik secara perseorangan atau meningkatkan kinerja pembelajaran kelompok.

Sedangkan menurut Rusman dkk (2011: 264) e-learning memiliki karakteristik, antara lain (a) interactivity (interaktivitas); (b) independency (kemandirian); (c) accessibility (aksesibilitas); (d) enrichment (pengayaan).

E-learning dapat didefinisikan sebagai sebuah bentuk teknologi informasi yang diterapkan di bidang pendidikan dalam bentuk dunia maya. Istilah e-learning lebih tepat ditujukan sebagai usaha untuk membuat sebuah transformasi proses pembelajaran yang ada di sekolah atau perguruan tinggi ke dalam bentuk digital yang dijembatani teknologi internet (Munir, 2009: 169). 
Seok (2008:725) menyatakan bahwa "e-learning is a new form of pedagogy for learning in the $21^{\text {st }}$ century. e-Teacher are $e$ learning instructional designer, facilitator of interaction, and subject matter experts". Penerapan e-learning untuk pembelajaran online pada masa sekarang ini sangatlah mudah dengan memanfaatkan modul Learning Management System yang mudah untuk diinstalasi dan dikelola seperti Moodle.

\section{LMS dan Moodle}

Fernando Alonso, dkk dalam Prasojo \& Rianto (2011:209) mengatakan bahwa "Learning Management Systems (LMS) or elearning platform are dedicated software tools intended to offer a virtual educational and/or online training environment". Learning Management System (LMS) adalah perangkat lunak yang digunakan untuk membuat materi perkuliahan online berbasiskan web dan mengelola kegiatan pembelajaran serta hasil-hasilnya. LMS juga memiliki fiturfitur yang dapat memenuhi semua kebutuhan dari pengguna dalam hal pembelajaran.

Moodle adalah paket software yang diproduksi untuk kegiatan belajar berbasis internet dan website. Moodle tersedia dan dapat digunakan secara bebas sebagai produk open source (terbuka source programnya). Sistem e-learning berbasis open source (Moodle) yang digunakan untuk model pembelajaran diharapkan dapat meningkatkan efisiensi dan efektivitas kinerja pengajar dan pemahaman pembelajar terhadap materi pembelajaran. Istilah Moodle singkatan dari Modular Object Oriented Dynamic Learning Environment yang berarti tempat belajar dinamis dengan menggunakan model berorientasi objek atau merupakan paket lingkungan pendidikan berbasis web yang dinamis dan dikembangkan dengan konsep berorientasi objek. Dalam penyediaannya Moodle memberikan paket software yang lengkap (Moodle, Apache, MySQL, dan PHP) (Munir, 2009: 180).

\section{Pembelajaran Efektif}

Penerapan teknologi dalam pembelajaran ditengarai dapat meningkatkan hasil pembelajaran. Pembelajaran berbasis teknologi informasi dan komunikasi akan berjalan efektif jika peran pengajar dalam pembelajaran adalah sebagai fasilitator pembelajaran atau memberikan kemudahan pembelajar untuk belajar bukan hanya sebagai pemberi informasi. Proses pembelajaran dengan memanfaatkan teknologi informasi dan komunikasi merupakan bimbingan dari pengajar untuk memfasilitasi pembelajaran pembelajar yang efektif (Munir, 2009: 3).

Pembelajaran yang efektif dapat dikatakan pembelajaran yang memanfaatkan teknologi informasi dan komunikasi secara optimal dalam proses pembelajarannya sebagai alat bantu. Salah satu pemanfaatan teknologi informasi dan komunikasi dalam pembelajaran adalah dengan memanfaatkan $e$ learning.

\section{Aspek Pengelolaan Pembelajaran E- learning}

\section{Perencanaan Pembelajaran}

Perencanaan pembelajaran pada dasarnya merupakan gambaran mengenai beberapa aktivitas dan tindakan yang akan dilakukan pada saat berlangsungnya proses pembelajaran. Dengan demikian dapat disimpulkan, aplikasi perencanaan pembelajaran yang berbasis e-learning memuat rencana, perkiraan dan gambaran umum kegiatan pembelajaran dengan memanfaatkan jaringan komputer, baik intranet maupun internet. Lingkup perencanaan pembelajaran meliputi empat komponen utama, yaitu tujuan, materi atau bahan ajar, kegiatan belajar mengajar, dan evaluasi. Hal tersebut sesuai dengan pernyataan Sisco (2010: 25) yaitu:

E-learning solution/strategy: "An $e$ learning solution of strategy is composed of content, technology, and services. Content includes courses, curriculum, and knowledge or skills development modules. Technology is the method used to deliver the content, including the internet and teleconferencing. Services relate to maintenance, content upgrades, and technical upgrades to both delivery and content. Understanding these components is an important first step to understanding what e-learning is and how it is "delivered"."

\section{Perancangan dan Pembuatan Materi}

Menurut Daniswara (2011: 2), dalam proses pembelajaran konten memegang peranan penting karena langsung berhubungan 
dengan proses pembelajaran peserta (siswa). Konten merupakan obyek pembelajaran yang menjadi salah satu parameter keberhasilan $e$ learning melalui jenis, isi dan bobot konten. Sistem e-learning harus dapat:

1. Menyediakan konten yang bersifat teacher-centered yaitu konten instruksional yang bersifat prosedural, deklaratif serta terdefinisi dengan baik dan jelas;

2. Menyediakan konten yang bersifat learner-centered yaitu konten yang menyajikan hasil (outcomes) dari instruksional yang terfokus pada pengembangan kreatifitas dan memaksimalkan kemandirian;

3. Menyediakan contoh kerja (work example) pada material konten untuk mempermudah pemahaman dan memberikan kesempatan untuk berlatih;

4. Menambahkan konten berupa games edukatif sebagai media berlatih alat bantu pembuatan pertanyaan.

Beberapa prinsip membuat situs pembelajaran atau website e-learning menurut Munir (2009: 191) antara lain:

1. Merumuskan tujuan pembelajaran;

2. Mengenalkan materi pembelajaran;

3. Memberikan bantuan dan kemudahan bagi pembelajar untuk mempelajari materi pembelajaran;

4. Memberikan bantuan dan kemudahan bagi pembelajar untuk mengerjakan tugas-tugas dengan perintah dan arahan yang jelas;

5. Materi pembelajaran yang disampaikan sesuai standar yang berlaku secara umum, serta sesuai dengan tingkat perkembangan pembelajar;

6. Materi pembelajaran disampaikan dengan sistematis dan mampu memberikan motivasi belajar, serta pada bagian akhir setiap materi pembelajaran dibuat rangkumannya;

7. Materi pembelajaran disampaikan sesuai dengan kenyataan, sehingga mudah dipahami, diserap, dan dipraktekkan langsung oleh pembelajar;

8. Metode penjelasannya efektif, jelas, dan mudah dipahami oleh pembelajar dengan disertai ilustrasi, contoh dan demonstrasi;

9. Sebagai alat untuk mengetahui keberhasilan pembelajaran, maka dapat dilakukan evaluasi dan meminta umpan balik (feedback) dari pembelajar.

\section{Penyampaian Pembelajaran}

Pembelajaran dengan e-learning merupakan pembelajaran dengan memanfaatkan teknologi internet untuk meningkatkan lingkungan belajar dengan konten yang kaya dengan cakupan yang luas. E-learning merupakan pemanfaatan media pembelajaran menggunakan internet, untuk mengirimkan serangkaian solusi yang dapat meningkatkan pengetahuan dan keterampilan. Hal tersebut sesuai dengan pernyataan Rossenberg (2006: 72) bahwa:

\section{"within the learning and performance architecture is e-learning not e-learning as it is traditionally practiced but a broader. E-learning is the use of Internet technologies to create and deliver a rich learning environment that includes a broad array of instruction and infor- mation resources and solutions, the goal of which is to enhance individual and organizational performance."}

Setiap metode pembelajaran harus mengandung rumusan pengorganisasian bahan pelajaran, strategi penyampaian, dan pengelolaan kegiatan dengan memperhatikan faktor tujuan belajar, hambatan belajar, karakteristik siswa, agar dapat diperoleh efektivitas, efisiensi, dan daya tarik pembelajaran (Miarso, 2004: 550).

\section{Media dan Interaktivitas Pembelajaran}

Social interaction may be of three types in e-learning and distance education:

1. Interaction between the learner and the originator of the teaching material (often a tenured research professor).

2. Interaction between the learner and a tutor (often a contracted instructor) who does not originate the learning materials, but who mediates between the original material and the learner, by providing guidance and/or assessment.

3. Interaction between the learner and other learners. (Bates, 2005: 61)

Berdasarkan pengertian dan fungsi media pembelajaran dapat disimpulkan bahwa media pembelajaran merupakan salah satu faktor eksternal yang berpengaruh terhadap keberhasilan kegiatan pembelajaran. Secara umum manfaat media pembelajaran adalah memperlancar interaksi antara guru dengan 
siswa sehingga kegiatan pembelajaran lebih efektif dan efisien. Keberhasilan e-learning ditunjang adanya interaksi maksimal antara guru dan siswa, antara siswa dan berbagai fasilitas pembelajaran, antara siswa dan siswa lainnya, serta adanya pola pembelajaran aktif dalam interaksi tersebut.

\section{Evaluasi Pelaksanaan Pembelajaran}

Evaluasi pembelajaran merupakan alat indikator untuk menilai pencapaian tujuantujuan yang telah ditentukan serta menilai proses pelaksanaan mengajar secara keseluruhan. Evaluasi bukan hanya sekedar menilai suatu aktivitas secara spontan dan insidental, melainkan merupakan kegiatan untuk menilai sesuatu secara terencana, sistematik, dan terarah berdasarkan tujuan yang jelas (Rusman dkk, 2011: 42).

Kegiatan evaluasi pelaksanaan pembelajaran e-learning dapat dilihat dari segi peningkatan pengetahuan dan keterampilan, lingkungan belajar, dan pengaruhnya. Evaluasi pelaksanaan e-learning merupakan proses menganalisis kualitas proses pembelajaran berbasis web (e-learning) dan sejauh mana ketercapaian dari proses e-learning tersebut untuk dapat dirasakan para pebelajar. Pelaksanaan evaluasi dilakukan sebagai bentuk penilaian terhadap berbagai komponen yang terdapat pada $e$-learning.

\section{Evaluasi Discrepancy}

Evaluasi model kesenjangan (discrepancy model) menurut Stufflebeam, Madaus, dan Kellaghan (2002: 127) adalah untuk mengetahui tingkat kesesuaian antara baku (standar) yang sudah ditentukan dalam program dengan kerja (performance) sesungguhnya dari program tersebut. Baku adalah kriteria yang ditetapkan, sedangkan kinerja adalah hasil pelaksanaan program.

\section{METODE PENELITIAN}

Penelitian ini merupakan penelitian evaluasi dengan model discrepancy. Evaluasi model discrepancy merupakan evaluasi kesenjangan program, melihat kesenjangan program yang terjadi antara yang diharapkan dengan pelaksanaan program (kenyataan). Standar pelaksanaan yang digunakan dalam evaluasi pembelajaran e-learning dalam penelitian ini adalah standar mutu pelaksanaan e-learning yang dikembangkan oleh Universitas Indonesia dalam buku pedoman penjaminan mutu penyelenggaraan e-learning Universitas Indonesia.

Penelitian dilaksanakan di SMK Telkom Sandhy Putra Purwokerto pada bulan Februari sampai dengan Juni 2012. Sampel guru diambil dengan metode purposive sampling yaitu dari populasi guru di SMK Telkom Sandhy Putra Purwokerto yang mengelola, memahami, atau terlibat langsung dengan pembelajaran e-learning. Sedangkan dari populasi siswa diambil sampel dengan cara proportional random sampling di SMK Telkom Sandhy Putra Purwokerto. Adapun penentuan ukuran sampel dari siswa dari populasi dalam penelitian digunakan rumus Slovin untuk mengetahui proporsi sampel, yaitu;

$$
\begin{array}{cl} 
& n=\frac{N}{N \cdot d^{2}+1} \\
\text { dimana: } & \\
\mathrm{n} & =\text { ukuran sampel } \\
\mathrm{N} & =\text { ukuran populasi } \\
\mathrm{d} & =\text { galat pendugaan }
\end{array}
$$

Tabel 1. Jumlah Populasi dan Sampel Penelitian

\begin{tabular}{lcccc}
\hline No. & Kelompok & Jurusan & Populasi & Sampel \\
\hline \multirow{3}{*}{1.} & \multirow{3}{*}{ Guru } & Normatif & 14 & 4 \\
& & Adaptif & 15 & 9 \\
& & Produktif & 13 & 9 \\
\hline & Total & & 42 & 22 \\
\hline \multirow{3}{*}{2.} & \multirow{2}{*}{ Siswa } & RPL & 275 & 97 \\
& & TJA & 245 & 87 \\
& & TKJ & 216 & 76 \\
\hline & & & 736 & 260 \\
\hline
\end{tabular}


Variabel yang diteliti dalam penelitian ini meliputi aspek pengelolaan pembelajaran e-learning yang terdiri dari variabel perencanaan pembelajaran, perancangan dan pembuatan materi, penyampaian pembelajaran, interaksi pembelajaran, dan evaluasi pelaksanaan pembelajaran e-learning.

Analisis data yang digunakan adalah analisis deskriptif dengan pendekatan kuanti- tatif yang menghasilkan kriteria keefektifan dari data kuantitatif instrumen angket penelitian. Analisis deskripsi data dalam penelitian ini dimaksudkan untuk mendiskripsikan dan memaknai keefektifan e-learning sebagai media pembelajaran di SMK Telkom Sandhy Putra Purwokerto, untuk mendeskripsikan data digunakan kriteria sebagai berikut:

Tabel 2. Kriteria penilaian keefektifan untuk analisis deskriptif

\begin{tabular}{ccc}
\hline No. & Rumus & Klasifikasi \\
\hline 1. & $M i+1,5 S D i \leq M \leq M i+3 S D i$ & Efektif \\
2. & $M i+0 S D i \leq M<M i+1,5 S D i$ & Cukup Efektif \\
3. & $M i-1,5 S D i \leq M<M i+0 S D i$ & Tidak Efektif \\
4. & $M i-3 S D i \leq M<M i-1,5 S D i$ & Sangat Tidak Efektif \\
\hline
\end{tabular}

Keterangan:

$M i=$ rerata ideal $=1 / 2$ (skor maksimum ideal + skor minimum ideal)

$S D i=$ simpangan deviasi $=1 / 6$ (skor maksimum ideal - skor minimum ideal)

$M \quad=$ skor empiris

\section{HASIL DAN PEMBAHASAN PENELITIAN}

Kecenderungan keefektifan pelaksanaan pembelajaran e-learning di SMK Telkon Sandhy Putra Purwokerto dapat disajikan pada Tabel 3.

Tabel 3. Distribusi Kecenderungan Keefektifan Standar Mutu Pelaksanaan E-learning sebagai Media Pembelajaran

\begin{tabular}{ccccc}
\hline No & Rumus & Frekuensi & Persentase & Klasifikasi \\
\hline 1. & $208 \leq \mathrm{M} \leq 256$ & 4 & $18,18 \%$ & Efektif \\
2. & $160 \leq \mathrm{M}<208$ & 17 & $77,27 \%$ & Cukup Efektif \\
3. & $112 \leq \mathrm{M}<160$ & 1 & $4,55 \%$ & Tidak Efektif \\
4. & $64 \leq \mathrm{M}<112$ & 0 & $0,00 \%$ & Sangat Tidak Efektif \\
\hline & Total & 22 & $100 \%$ & \\
\hline
\end{tabular}

Berdasarkan tabel 3 menunjukkan pernyataan guru, bahwa pelaksanaan pembelajaran e-learning sebagai media pembelajaran di SMK Telkom Sandhy Putra Purwokerto secara keseluruhan cukup efektif dengan tingkat kecenderungan sebesar $77,27 \%$. Akan tetapi, bagi sekelompok pengajar, pelaksanaan pembelajaran $e$-learning ini tidak efektif.

Adapun ketercapaian keefektifan masing-masing komponen standar mutu pelaksanaan e-learning di SMK Telkom Sandhy Putra Purwokerto disajikan pada Gambar 1.

Berdasarkan gambar 1, dapat diketahui persentase keefektifan standar mutu pelak- sanaan implementasi e-learning dari masingmasing variabel tergolong cukup efektif. Keefektifan komponen perencanaan pembelajaran sebesar 74,50\%, komponen perancangan dan pembuatan materi sebesar $75,27 \%$, komponen penyampaian pembelajaran sebesar $75 \%$, komponen interaksi pembelajaran sebesar $66,10 \%$, dan komponen evaluasi pelaksanaan sebesar $69,01 \%$. Kesenjangan dari ketercapaian masing-masing komponen pelaksanaan e-learning di SMK Telkom Sandy Putra Purwokerto adalah sebagai berikut: 


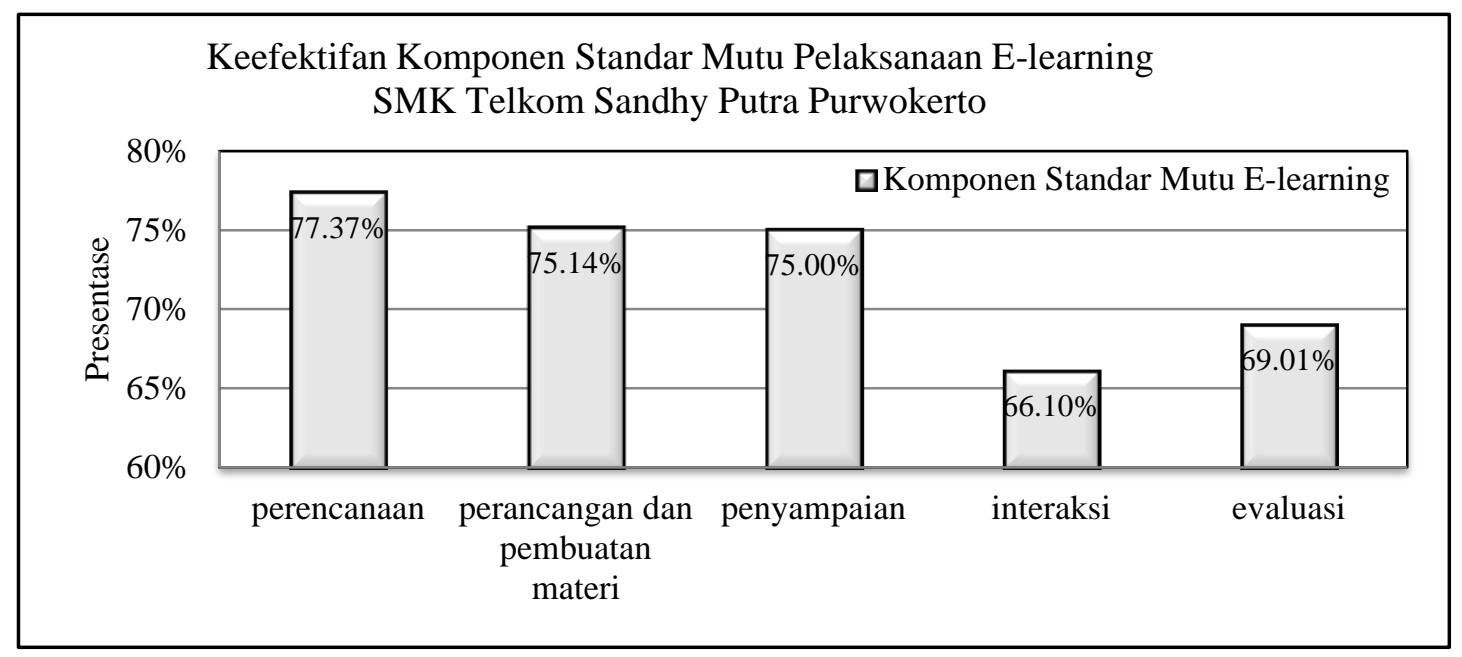

Gambar 1. Keefektifan Komponen Standar Mutu Pelaksanaan E-learning SMK Telkom Sandhy Putra Purwokerto

\section{Ketercapaian Standar Mutu Perencanaan Pembelajaran E-learning}

Kriteria penilaian indikator perencanaan pembelajaran e-learning dapat dilihat dari Tabel 4.

Tabel 4. Penilaian Indikator Standar Mutu Perencanaan E-learning

\begin{tabular}{clcc}
\hline No & \multicolumn{1}{c}{ Indikator Standar Mutu Perencanaan } & Persentase & Kategori \\
\hline 1 & $\begin{array}{l}\text { Pembelajaran yang dilaksanakan harus memperoleh } \\
\text { persetujuan kepala sekolah (stake holder) }\end{array}$ & $71,59 \%$ & Sesuai \\
2 & $\begin{array}{l}\text { Pengajar dan siswa harus memiliki akses terhadap } \\
\text { intranet dan internet }\end{array}$ & $83,86 \%$ & $\begin{array}{l}\text { Sangat } \\
\text { Sesuai }\end{array}$ \\
3 & $\begin{array}{l}\text { Pengajar harus memiliki akses terhadap fasilitas } \\
\text { pengembangan pembelajaran berbasis } e \text {-learning }\end{array}$ & Sesuai \\
& $\begin{array}{l}\text { Tersedia Rencana Pelaksanaan Pembelajaran (RPP) dan } \\
\text { silabus dalam perencanaan model pembelajaran } e-\end{array}$ & $76,14 \%$ & Sesuai \\
learning & $\begin{array}{l}\text { Tersedia akses terhadap fasilitas pelatihan } \\
\text { penyelenggaraan } e \text {-learning }\end{array}$ & $71,59 \%$ & Sesuai \\
\hline
\end{tabular}

Kesenjangan pada komponen perencanaan pembelajaran e-learning yaitu belum adanya komitmen dari sekolah untuk melaksanakan pembelajaran e-learning secara optimal, proses pembelajaran belum diarahkan pada pembelajaran berbasis e-learning. Sehingga tingkat urgensi pem-belajaran menggunakan media e-learning masih kurang.

Rekomendasi untuk meningkatkan keefektifan perencanaan pembelajaran $e$ learning yaitu perlu memperhatikan aspek utama perencanaan implementasi e-learning sebagai langkah awal pemanfaatan e-learning sebagai media pembelajaran. Hal yang perlu diperhatikan antara lain:

1. Pelaksanaan perencanaan pembelajaran dengan e-learning dapat diawali dengan analisis kebutuhan untuk mengetahui kondisi lingkungan sekolah dan pembelajaran pada umumnya agar mampu melaksanakan pembelajaran dengan $e$ learning secara optimal

2. Ketersediaan jaringan (network), merencanakan persiapan dari segi infrastruktur dan teknologi 
3. Ketersediaan fasilitas sekolah antara lain ketersediaan hardware dan software, serta ruang kelas atau laboratorium komputer sebagai ruang belajar dengan memanfaatkan metode blended learning yang menggunakan $e$-learning

4. Guru membuat atau menyediakan Rancangan Pelaksanaan Pembelajaran (RPP) dan silabus yang berkaitan dengan pelaksanaan pembelajaran konvensional dan pelaksanaan pembelajaran dengan $e$ learning

5. Guru merumuskan tujuan pembelajaran yang jelas

6. Guru merencanakan materi ajar untuk menyediakannya dalam e-learning. Materi diberikan sesuai dengan analisa kebutuhan dan kemampuan siswa serta disesuaikan dengan kompetensi yang dibutuhkan

7. Agar mencapai hasil yang maksimal, pihak sekolah harus membuat kebijakan agar guru melaksanakan pembelajaran $e$ learning dengan optimal dan siswa tertarik untuk belajar dengan menggunakan e-learning sekolah

\section{Ketercapaian Standar Mutu Perancangan dan Pembuatan Materi E-learning}

Tabel 5 menunjukkan penilaian guru terhadap standar mutu perancangan dan pembuatan materi pembelajaran e-learning yang terdiri dari 5 indikator.

Tabel 5. Penilaian Indikator Standar Mutu Perancangan dan Pembuatan Materi E-learning

\begin{tabular}{|c|c|c|c|}
\hline No & $\begin{array}{c}\text { Indikator Standar Mutu Perancangan dan Pembuatan } \\
\text { Materi }\end{array}$ & Persentase & Kategori \\
\hline 1 & $\begin{array}{l}\text { Materi harus sesuai dengan kurikulum dan media } \\
\text { elektronik yang tersedia }\end{array}$ & $78,03 \%$ & Sesuai \\
\hline 2 & Materi disiapkan oleh pakar di bidang ilmu terkait & $75,00 \%$ & Sesuai \\
\hline 3 & $\begin{array}{l}\text { Perancangan dan pembuatan materi harus sesuai } \\
\text { dengan karakteristik pembelajaran e-learning }\end{array}$ & $79,55 \%$ & Sesuai \\
\hline 4 & $\begin{array}{l}\text { Materi harus tersedia dan dapat diakses siswa tanpa } \\
\text { terikat tempat dan waktu }\end{array}$ & $78,41 \%$ & Sesuai \\
\hline 5 & $\begin{array}{l}\text { Menjalankan penyelenggaraan e-learning sesuai } \\
\text { dengan kode etik dan peraturan yang berlaku }\end{array}$ & $65,91 \%$ & Sesuai \\
\hline
\end{tabular}

Kesenjangan terkait dengan komponen perancangan dan pembuatan materi e-learning pada pelaksanaan pembelajaran e-learning di SMK Telkom Sandhy Putra Purwokerto yaitu pembuatan e-learning belum didaftarkan hak ciptanya, sehingga belum memenuhi kaidah pembelajaran berbasis internet, serta beberapa guru belum memahami secara mendalam mengenai pengelolaan course dalam e-learning.

Rekomendasi untuk komponen perancangan dan pembuatan materi e-learning yaitu aspek perancangan dan pembuatan materi merupakan kegiatan yang dibutuhkan dalam mengelola pembelajaran e-learning yang berkaitan dengan proses pembelajaran oleh guru. Untuk mempersiapkan pelaksanaan perancangan dan pembuatan materi, sebainya perlu diperhatikan:

1. Ketersediaan hardware dan software, dalam hal ini ketersediaan hardware yang mendukung ditinjau dari sisi server dan client, LAN WAN, switch, dan bandwidth, serta ketersediaan software sistem dan software aplikasi untuk mengembangkan media pembelajaran berbasis e-learning

2. Kesiapan brainware untuk mengelola hardware dan software

3. Penerapan pembelajaran multimedia yang bersifat interaktif untuk mendorong peserta didik aktif belajar

4. Guru membuat bahan ajar yang mudah dikelola dan diperbaharui

5. Kemudahan akses bahan ajar.

6. Guru mendesain materi ajar dengan memperhatikan tampilan, interaksi/aspek interaktivitas, kontrol (melalui beberapa mekanisme antara lain menyusun menu, panel, dan fasilitas bantuan yang memperjelas mekanisme materi ajar), bentuk atau jenis materi, dan susunan materi. 


\section{Ketercapaian Standar Mutu Penyampaian} Pembelajaran E-learning

Tabel 6 menunjukkan ketercapaian indikator standar mutu penyampaian pem- belajaran e-learning di SMK Telkom Sandhy Putra Purwokerto.

Tabel 6. Penilaian Indikator Standar Mutu Penyampaian Materi E-learning

\begin{tabular}{clcc}
\hline No & \multicolumn{1}{c}{ Indikator Standar Mutu Penyampaian } & Persentase & Kategori \\
\hline 1 & $\begin{array}{l}\text { Materi minimum tersedia dalam presentasi } \\
\text { elektronik (misalnya power point) }\end{array}$ & $77.84 \%$ & Sesuai \\
2 & $\begin{array}{l}\text { Penyampaian materi harus sesuai dengan program } \\
\text { mapping yang telah ditentukan }\end{array}$ & $77.08 \%$ & Sesuai \\
3 & $\begin{array}{l}\text { Materi harus menarik dari segi isi dan layout, } \\
\text { terkini, serta bebas dari kesalahan }\end{array}$ & $74.62 \%$ & Sesuai \\
4 & $\begin{array}{l}\text { Harus tersedia fasilitas tatap muka (blended } \\
\text { learning) }\end{array}$ & Sesuai \\
& $\begin{array}{l}\text { Harus tersedia fasilitas pendukung yang } \\
\text { memudahkan siswa melakukan akses bagian- } \\
\text { bagian materi, misalnya navigasi dalam presentasi } \\
\text { elektronik }\end{array}$ & $73.86 \%$ & Sesuai \\
\hline
\end{tabular}

Kesenjangan pada komponen penyampaian pembelajaran e-learning SMK Telkom Sandhy Putra Purwokerto yaitu strategi belajar dengan menggunakan multimedia belum sepenuhnya diadaptasi dan kurangnya penambahan materi pembelajaran yang bersifat interaktif untuk setiap mata pelajaran.

Rekomendasi untuk komponen penyampaian pembelajaran e-learning, yaitu guru memperhatikan aspek-aspek penting dalam penyampaian pembelajaran dengan $e$ learning untuk meningkatkan metode penyampaian pembelajarannya. Hal-hal yang perlu diperhatikan antara lain:

1. Menentukan sasaran dan tujuan pembelajaran

2. Membuat isi pembelajaran, dimana dan bagaimana materi pembelajaran yang ber-sifat interaktif dapat digunakan secara efektif

3. Merancang proses pembelajaran serta operasionalnya
4. Meningkatkan keterampilan seorang peng-ajar yang berkelanjutan melalui berbagai pelatihan menggunakan multimedia kom-puter

5. Mengetahui pengoperasian dan pemeliharaan hardware serta pengetahuan tentang pemilihan software pembelajaran

6. Mengintegrasikan pembelajaran melalui e-learning dengan kurikulum

7. Mengetahui teknik-teknik pembelajaran menggunakan komputer

8. Lebih peka terhadap perkembangan teknologi terkini (up to date)

\section{Ketercapaian Standar Mutu Interaksi Pembelajaran E-learning}

Tabel 7 menunjukkan tingkat penilaian indikator standar mutu interaksi pembelajaran e-learning di SMK Telkom Sandhy Putra Purwokerto berdasarkan penyataan guru.

Tabel 7. Penilaian Indikator Standar Mutu Interaksi Pembelajaran E-learning

\begin{tabular}{clcc}
\hline No. & \multicolumn{1}{c}{ Standar Mutu Interaksi } & Skor & Kategori \\
\hline 1. & $\begin{array}{l}\text { Pembelajaran dirancang untuk menjamin } \\
\text { terjadinya interaksi antara siswa, guru-siswa, } \\
\text { siswa-materi }\end{array}$ & $68,18 \%$ & Sesuai \\
2. $\begin{array}{l}\text { Interaksi harus dapat dilakukan baik secara } \\
\text { synchronous maupun asynchronous }\end{array}$ & $65,06 \%$ & Sesuai \\
\hline
\end{tabular}


Kesenjangan komponen interaksi pembelajaran e-learning di SMK Telkom Sandhy Putra Purwokerto yaitu menyediakan interaksi pembelajaran melalui e-learning. Rekomendasi untuk komponen interaksi pembelajaran dengan e-learning yaitu pemanfaatan jaringan komputer untuk meningkatkan interaktivitas pembelajaran. Jaringan komputer dapat dimanfaatkan dalam pembelajaran e-learning sehingga guru dapat meningkatkan efektivitas pembelajaran dengan melaksanakan penyebaran informasi, komunikasi dua arah melalui jaringan internet, sarana diskusi, dan sarana memberikan tugas atau materi.

Interaksi pembelajaran dapat berjalan apabila terdapat pengelola pembelajaran (guru), sumber belajar, subyek pembelajar (siswa), interaksi antara pengajar/guru. Pengelolaan pembelajaran dapat dilakukan oleh guru, sehingga guru memberikan peran aktif dalam sistem pembelajaran termasuk dalam $e$ learning. Siswa tidak dapat belajar dengan baik, serta mengakses sistem pembelajaran jika tidak ada jaringan komputer dan kontenkonten pembelajaran.

\section{Evaluasi Pelaksanaan Pembelajaran $E$ - learning}

Tabel 8 menunjukkan indikator evaluasi terhadap guru, siswa, isi/konten, proses, penyelenggara, pelaksanaan, dan materi.

Tabel 8. Penilaian Indikator Standar Mutu Evaluasi Pelaksanaan E-learning

\begin{tabular}{clcc}
\hline No. & \multicolumn{1}{c}{ Standar Mutu Evaluasi } & Skor & Kategori \\
\hline & $\begin{array}{l}\text { Harus ada evaluasi terhadap guru, siswa, isi/konten } \\
\text { (materi, tugas, kuis), proses (keaktifan, peer }\end{array}$ & & \\
1. $\begin{array}{l}\text { asessment), penyelenggara (peraturan, tata cara proses } \\
\text { registrasi), pelaksanaan (dukungan fasilitas dan teknis } \\
\text { selama penyelenggaraan } \text { e-learning), materi } \\
\text { (kesesuaian dengan silabus, kemudahan dipahami, } \\
\text { kemudahan akses) }\end{array}$ & 69,01 & Sesuai \\
\hline
\end{tabular}

Kesenjangan pada komponen evaluasi pelaksanaan pembelajaran e-learning SMK Telkom Sandhy Putra Purwokerto yang mendasar yaitu guru melaksanakan penilaian dan melihat keaktifan siswa dalam pembelajaran e-learning, serta guru memberikan tugas melalui e-learning. Hal tersebut belum dilaksanakan secara optimal oleh semua guru dalam setiap kegiatan pembelajarannya.

Rekomendasi untuk komponen evaluasi pelaksanaan pembelajaran e-learning yaitu dilaksanakan penilaian mengenai keberhasilan program e-learning. Kesiapan pelaksanaan pembelajaran dengan $e$-learning dapat dilihat dari tiga dimensi, yaitu motivasi untuk menggunakan $e$-learning, kompetensi atau kemampuan yang cukup untuk mengelola dan mengikuti pembelajaran e-learning, dan sumberdaya yang meliputi fasilitas, akses, dan teknologi yang memadai. Keberhasilan pembelajaran dengan media e-learning berhubungan dengan usaha yang konsisten dan terintegrasi dari siswa, sekolah, guru/fasilitator, staf penunjang, dan administrator.

\section{KESIMPULAN}

Berdasarkan hasil analisis keefektifan e-learning sebagai media pembelajaran di SMK Telkom Sandhy Putra Purwokerto berdasarkan standar mutu pelaksanaan $e$ learning dapat disimpulkan bahwa:

1. Aspek perencanaan pembelajaran $e$ learning termasuk dalam kategori cukup efektif dengan persentase tingkat kecenderungan sebesar 77,57\%.

2. Aspek perancangan dan pembuatan materi menunjukkan kategori cukup efektif dengan persentase tingkat kecenderungan sebesar $75,14 \%$.

3. Aspek penyampaian atau metode penyampaian pembelajaran e-learning menunjukkan kategori cukup efektif dengan tingkat kecenderungan $75 \%$.

4. Aspek interaksi pembelajaran menunjukkan kategori cukup efektif dengan tingkat kecenderungan $66,10 \%$.

5. Aspek evaluasi pelaksanaan pembelajaran e-learning menuunjukkan kategori 
cukup efektif dengan kecenderungan sebesar 69,01\%.

6. Kriteria pelaksanaan pembelajaran $e$ learning sebagai media pembelajaran di SMK Telkom Sandhy Putra Purwokerto secara keseluruhan cukup efektif dengan tingkat kecenderungan sebesar 77,27\%.

7. Faktor-faktor pendukung pelaksanaan $e$ learning di SMK Telkom Sandhy Putra Purwokerto antara lain: kesiapan SDM untuk meningkatkan pembelajaran $e$ learning, fasilitas software untuk mengembangkan media pembelajaran, fasilitas sarana internet di lingkungan sekolah, dan kebutuhan pelaksanaan media pembelajaran e-learning di SMK Telkom Sandhy Putra Purwokerto untuk meningkatkan dan menambah aktivitas pembelajaran di kelas. Sedangkan faktor penghambat pelaksanaan e-learning di SMK Telkom Sandhy Putra Purwokerto antara lain: belum adanya lisensi dan hak cipta atas pembelajaran e-learning yang telah dilaksanakan, kurangnya motivasi untuk guru dalam mengembangkan pembelajaran e-learning dikarenakan tersedianya fasilitas belajar yang lain di kelas, dan masih terdapat guru yang belum memahami tentang pengelolaan course dalam e-learning, keterbatasan waktu pengelolaan pembelajaran $e$ learning, keterbatasan fasilitas dalam hal pendidikan dan pelatihan untuk meningkatkan kemampuan e-learning serta dukungan untuk melaksanakan pembelajaran e-learning, kurangnya komitmen yang dari sekolah maupun guru mengenai pengembangan pembelajaran e-learning, serta dana yang diperlukan untuk pelaksanaan e-learning masih terbatas.

\section{SARAN}

Pelaksanaan pembelajaran e-learning di SMK Telkom Sandhy Putra Purwokerto perlu mendapatkan dukungan penuh pimpinan dengan menetapkan dalam kebijakan sekolah melalui sistem reward atau penghargaan terhadap guru yang melaksanakan pembelajaran e-learning dalam meningkatkan mutu pembelajarannya, serta pelaksanaan secara formal dengan memiliki hak cipta dan lisensi dari pelaksanaan e-learning di SMK Telkom Sandhy Putra Purwokerto.
Model pembelajaran e-learning di SMK Telkom Sandhy Putra Purwokerto dapat dijadikan sebagai alat bantu pada pembelajaran di sekolah kejuruan yang memiliki persentase pembelajaran di sekolah kejuruan antara teori dengan persentase yang lebih sedikit dibandingkan dengan praktek. $E$ learning dapat dimanfaatkan untuk meningkatkan pemahaman materi dan memperluas sumber materi ajar maupun menambah aktivitas belajar serta membantu guru dalam mengefisienkan waktu pembelajaran di dalam kelas.

SMK Telkom Sandhy Putra Purwokerto telah memiliki e-learning yang aktif dan memiliki sarana dan prasarana pembelajaran online, sehingga e-learning dapat dimanfaatkan untuk proses pembelajaran dan meningkatkan aktivitas belajar siswa, juga dapat dimanfaatkan sebagai media promosi sekolah di publik dan juga media pembelajaran yang dapat dimanfaatkan sebagai fasilitas pembelajaran online

\section{DAFTAR PUSTAKA}

Bates, A. W., \& Poole, G. (2003). Effective teaching with technology in higher education. San Fransisco: Jossey Bass.

Bates, A. W. \& T. Bates. (2005). Technology, e-learning and distance education: second edition. New York: Routledge Press.

Clark, R.C. \& Mayer, R.E. (2008). E-learning and the science of instruction: proven guidelines for consumers and designers of multimedia learning, second edition. San Francisco: John Wiley \& Sons, Inc.

Lantip Diat Prasojo \& Riyanto. (2011). Teknologi informasi pendidikan. Yogyakarta: Gava Media.

Mungania, Peni. (2003). The seven e-learning barriers facing employees. Diambil pada tanggal 20 Juli 2012, dari http://aerckenya.org/docs/ElearningRep ort.pdf.

Munir. (2009). Pembelajaran jarak jauh berbasis teknologi informasi dan komunikasi. Bandung: Alfabeta.

Okki Mahendra Daniswara. (2011). Aspek penting pembangunan e-learning 
system. Diambil pada tanggal 21 Agustus 2011, dari http://mahendraokki.unpad.ac.id/wp-content/aspekpenting-pembangunan-e-learning system.pdf

Rusman, dkk. (2011). Pembelajaran berbasis teknologi informasi dan komunikasi, mengembangkan profesionalitas guru. Jakarta: PT. Raja Grafindo.

Seok, Soonhwa. (2008). The aspect of elearning. International Journal on ELearning, Proquest, 7(4), 725-741.
Sisco, Ashley. (2010). Nations First for elearning of effectiveness the Optimizing. Ottawa: The Conference Board of Canada.

Stufflebeam, D. L., Madaus, G. F., \& Kellaghan, T. (2002). Evaluation models, viewpoints on educational ang human services evaluation, second edition. New York: Kluwer Academic Publisher. 